\title{
CrystEngComm
}

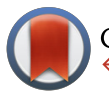

CrossMark -click for updates

Cite this: CrystEngComm, 2016, 18 5393

Received 2nd May 2016,

Accepted 28th May 2016

DOI: $10.1039 / c 6 c e 01025 c$

www.rsc.org/crystengcomm

\section{Halogen and hydrogen bonds in compressed pentachloroethane $\dagger$}

\author{
Maciej Bujak, ${ }^{* a}$ Marcin Podsiadło ${ }^{b}$ and Andrzej Katrusiak*b
}

\begin{abstract}
In pentachloroethane, $\mathrm{C}_{2} \mathrm{HCl}_{5}$, high pressure initially strongly compresses the $\mathrm{C}-\mathrm{H} \cdots \mathrm{Cl}$ bonds in phase I; however, in phase II which is stable above $0.62 \mathrm{GPa}$ the role of hydrogen bonds is diminished and molecular aggregation is dominated by halogen bonds $\mathrm{Cl} \cdots \mathrm{Cl}$. Both phases have been determined by $\mathrm{X}$-ray diffraction and the phase diagram of $\mathrm{C}_{2} \mathrm{HCl}_{5}$ has been outlined. The transition between phases I and II retains some relation between their structures and reduces the symmetry from class $\mathrm{mmm}$ (space group Pnma) to $2 / m$ (space group $P 2_{1} / n 11$ ). The discontinuous transition, with the shear strain exceeding $21^{\circ}$, is so strong that its progress can be visually observed even for powdered samples. The single-crystal growth suggests a surface-roughening transition, as phase I grows in the form of dendrites combining into oval plates, while phase II forms prisms with sharp edges.
\end{abstract}

\section{Introduction}

Ethane belongs to the simplest alkanes, present as building blocks in many organic molecules. Therefore, ethane and its derivatives are valuable model compounds for studying molecular aggregation and conformations. The application of halogenated alkanes for improving the technological properties of fuels used for airplanes and improving their security requires information about the structure, aggregation, interactions and thermodynamic properties of these compounds. ${ }^{1}$ Halo-substituted methanes exhibit a variety of aggregation modes involving $\mathrm{CH}^{\cdots} \cdots$ halogen and halogen $\cdots$ halogen interactions. ${ }^{2}$ Haloethanes additionally can change their conformation due to the relatively soft rotations about the $\mathrm{C}-\mathrm{C}$ bond. Furthermore, the molecules can be orientationally and conformationally disordered. ${ }^{3}$ Consequently, haloethanes exist in polymorphic forms and undergo phase transitions involving order-disorder, conformational conversions and changing types of intermolecular interactions. ${ }^{3 b, 4}$ Presently, we have studied the aggregation of pentachloroethane, $\mathrm{C}_{2} \mathrm{HCl}_{5}$ (PCE). Its staggered conformation is strongly favored, and the $\mathrm{Cl} \cdots \mathrm{Cl}$ contacts are most likely to dominate its intermolecular interactions. We were particularly interested in the role of $\mathrm{CH}^{\cdots} \mathrm{Cl}$ contacts, which are considerably shorter than halogen bonds $\mathrm{Cl} \cdots \mathrm{Cl}$ and for this reason could be excluded from the main cohesion forces. ${ }^{5}$ We have applied high pres-

\footnotetext{
${ }^{a}$ Faculty of Chemistry, University of Opole, Oleska 48, 45-052 Opole, Poland. E-mail: mbujak@uni.opole.pl; Tel: +48 (77) 4527159

${ }^{b}$ Faculty of Chemistry, Adam Mickiewicz University, Umultowska 89b, 61-614 Poznań, Poland. E-mail: katran@amu.edu.pl; Tel: +48 (61) 8291590

$\dagger$ Electronic supplementary information (ESI) available: Detailed experiment and structural descriptions. CCDC 1477284-1477289. For ESI and crystallographic data in CIF or other electronic format see DOI: 10.1039/c6ce01025c
}

sure for these studies, because it is the most efficient method for modifying the molecular structure and arrangement in crystals. Therefore, high pressure is increasingly often used for generating new polymorphs of pharmaceutical, energetic and other materials. ${ }^{6}$

\section{Results and discussion}

When isothermally compressed in a diamond-anvil cell (DAC), the liquid PCE sample first freezes in orthorhombic phase I and then transforms into monoclinic phase II (see Fig. 1 and Movie S1, ESI $\dagger$ ). We determined its structure at $295 \mathrm{~K} / 0.36 \mathrm{GPa}$ and $295 \mathrm{~K} / 0.45 \mathrm{GPa}$ (Table 1). Still higher pressure of $c a .295 \mathrm{~K} / 0.62 \mathrm{GPa}$ induces a reversible discontinuous transition to monoclinic phase II (PCE-II, Fig. 2 and S1, ESI $\dagger$ ). We determined the high-pressure structures of PCE-II,

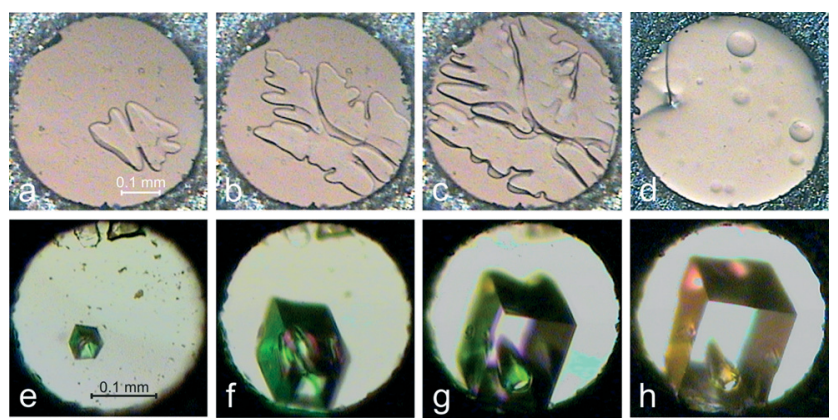

Fig. 1 Stages of isochoric growth of the PCE-I single crystal initially in the 'snowflake' dendritic, rounded nucleus grown from neat liquid at ca. $350 \mathrm{~K}$ and eventually fully filling the DAC chamber at $295 \mathrm{~K} / 0.36$ GPa (a-d), and the sample with well-defined faces of PCE-II grown from the PCE : propan-2-ol 1:1 (vol.) mixture at $0.76 \mathrm{GPa}$ (e-h). Ruby chips for pressure calibration lie at the upper edge of the chambers. 
Table 1 Selected crystal data of PCE phases I and II at $295 \mathrm{~K}$. Note the exchanged axes $[x]$ and $[y]$ between phases I and II

\begin{tabular}{lllll}
\hline & PCE-I & \multicolumn{3}{l}{ PCE-II } \\
\hline $\begin{array}{l}\text { Pressure, } \\
\text { GPa }\end{array}$ & $0.36(2)$ & $0.45(2)$ & $0.76(2)$ & $1.00(2)$ \\
$\begin{array}{l}\text { Crystal } \\
\text { system }\end{array}$ & Orthorhombic & Orthorhombic & Monoclinic & Monoclinic \\
Space & Pnma & Pnma & P2 $1 / n$ & $P 2_{1} / n$ \\
group & & & & \\
$a, \AA$ & $10.325(8)$ & $10.210(7)$ & $9.5190(17)$ & $9.4194(9)$ \\
$b, \AA$ & $11.063(3)$ & $11.039(3)$ & $11.3199(4)$ & $11.2200(3)$ \\
$c, \AA$ & $6.0870(10)$ & $6.0415(9)$ & $6.393(3)$ & $6.379(4)$ \\
$\beta, \circ$ & 90 & 90 & $111.78(3)$ & $111.75(3)$ \\
$V, \AA^{3}$ & $695.3(6)$ & $680.9(5)$ & $639.7(3)$ & $626.2(4)$ \\
$Z, Z^{\prime}$ & $4,0.5$ & $4,0.5$ & 4,1 & 4,1 \\
$\rho$, g cm ${ }^{-3}$ & 1.932 & 1.973 & 2.100 & 2.146 \\
$R_{1}\left(I>2 \sigma_{\mathrm{I}}\right)$ & 0.1066 & 0.0997 & 0.0409 & 0.0282 \\
$R_{1}($ all data) & 0.1260 & 0.1147 & 0.0501 & 0.0305 \\
& & & &
\end{tabular}

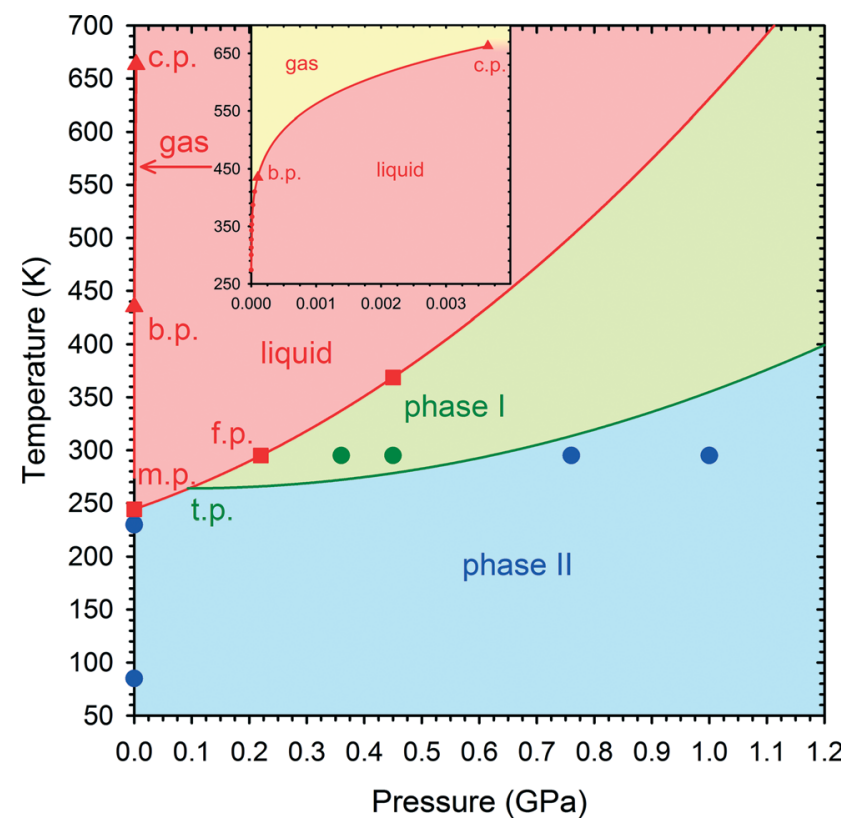

Fig. 2 The phase diagram of PCE based on visual observation of the liquid freezing in the diamond-anvil cell (red squares), X-ray diffraction data (green and blue circles) and literature information (cf. Fig. S1, ESI $\dagger$ ). Triple point (t.p.) is deduced from the absence of transition between phases I and II at 0.1 MPa (see the DSC plot in Fig. S2, ESI $\dagger$ ).

crystallized from the $1: 1(\mathrm{v} / \mathrm{v})$ mixture of PCE and propan-2ol, at $295 \mathrm{~K} / 0.76 \mathrm{GPa}$ and $295 \mathrm{~K} / 1.00 \mathrm{GPa}$.

The comparison of unit-cell dimensions, positions of molecules in the unit cells (Fig. 3) and crystal symmetry groupsubgroup relations indicate that phases I and II are structurally related. The transition reduces the symmetry of spacegroup Pnma by eliminating the mirror plane and glide plane $a$. In order to comply with the convention, axes $[x]$ and $[y]$ of phase II have been exchanged and angle $\beta$ becomes monoclinic in space group $P 12_{1} / n 1$ (Table 1 ). The lattice relation between phases I and II implies that parameter $a_{\mathrm{I}}$ corresponds to $b_{\mathrm{II}}$ and $b_{\mathrm{I}}$ corresponds to $a_{\mathrm{II}}$ (Fig. 4 , the subscripts indicate the phases). It also shows that the transition induces a huge strain between phases I and II: axis $[x]$ of phase I expands by over $10 \%$, axis $[y]$ shrinks by nearly $-15 \%$, axis $[z]$ expands by about $6 \%$ and a huge shear strain exceeds $21^{\circ}$. All these changes mutually compensate and the resultant volume drop is relatively small.

In both phases I and II, the PCE molecules retain the staggered conformation. In phase I, the molecules are located on mirror planes. Each molecule is involved in two $\mathrm{Cl} \cdots \mathrm{Cl}$ contacts and two $\mathrm{CH}^{\cdots} \mathrm{Cl}$ bonds; the $\mathrm{H} \cdots \mathrm{Cl}$ distance becomes shorter than the sum of van der Waals radii above $0.45 \mathrm{GPa}$ (ref. 7) (Table 2, Fig. 3a).

The pattern of halogen bonds changes between phases I and II (Fig. 3). In phase I at $295 \mathrm{~K} / 0.45 \mathrm{GPa}$, the $\mathrm{Cl} \cdots \mathrm{Cl}$ bonds arrange molecules into zigzag chains along axis $[y]$ and the voids also assume a zigzag motif of the same direction and period, but much larger amplitude (Fig. 3a). In phase II, the $\mathrm{Cl} \cdots \mathrm{Cl}$ contacts are more numerous and they form a 3-dimensional pattern (Fig. 3b).

The compression of PCE at room temperature (Fig. 4 and $\mathrm{S} 3, \mathrm{ESI} \dagger$ ) changes abruptly its volume by $-1.3 \%$ when the liquid freezes at $0.22 \mathrm{GPa}$. This molecular-volume drop by 2.4 $\AA^{3}$ is $c a$. twice smaller than that in 1112TCE (ca. 3.8 $\AA^{3}$, $-2.5 \%)^{4 a}$ and it is the smallest volume change reported for chloroethanes, ${ }^{3 b, 4 a-c}$ which also corresponds to the smallest reduction of averaged intermolecular distances for PCE in the pressure region immediately before and above freezing. Then the compression of phase II, between 0.62 and $1.9 \mathrm{GPa}$, is on average almost three times smaller than that of phase I between 0.22 and $0.62 \mathrm{GPa}$. The volume discontinuity is very small, but different compression rates clearly distinguish the regions of phases I and II.

In phases I and II, the intermolecular $\mathrm{Cl} \cdots \mathrm{Cl}$ contacts have been compressed to 3.37 and $3.28 \AA$, respectively. Contacts $\mathrm{H} \cdots \mathrm{Cl}$ are the strongest compressed contacts in phase I, much stronger than contacts $\mathrm{Cl} \cdots \mathrm{Cl}$. According to the $\mathrm{CH} \cdots \mathrm{Cl}$ bond compression within phase $\mathrm{I}$, it can be estimated that the $\mathrm{H} \cdots \mathrm{Cl}$ distance is less than 2.8 or even $2.7 \AA$ before the transition to phase II. In phase II, the $\mathrm{H} \cdots \mathrm{Cl}$ distance is longer than $3.0 \AA$ and it increases with pressure (Fig. 5). It may indicate that high pressure reduces the potential energy $\left(E_{\mathrm{p}}\right)$ associated with the $\mathrm{CH} \cdots \mathrm{Cl}$ bonds in phase I. In phase II, two $\mathrm{H} \cdots \mathrm{Cl}$ contacts, somewhat longer than those in phase I, become longer as pressure increases. At the same time, the compression of contacts $\mathrm{Cl} \cdots \mathrm{Cl}$ in phase II is weaker than that in phase I. It thus appears that the structural rearrangement between phases I and II reverses the compression rate of contacts $\mathrm{Cl} \cdots \mathrm{Cl}$ and $\mathrm{H} \cdots \mathrm{Cl}$ (Tables 2 and 3 ; Fig. 5 and S4, ESI $\dagger$ ). A relatively long, but commensurate with the sum of the van der Waals radii ${ }^{7} \mathrm{H}^{\cdots} \mathrm{Cl} / \mathrm{CH} \cdots \mathrm{Cl}$ intermolecular hydrogen bond was found only in the structure of PCE-I determined at $295 \mathrm{~K} / 0.45 \mathrm{GPa}$.

The Hirshfeld two-dimensional fingerprint plots show that the $\mathrm{H} \cdots \mathrm{Cl}$ contacts are the most different feature of PCE-I and II (Fig. S5, ESI $\dagger$ ), while in both polymorphs the dominant role is played by $\mathrm{Cl} \cdots \mathrm{Cl}$ contacts (Tables 2 and 3 ). It is 


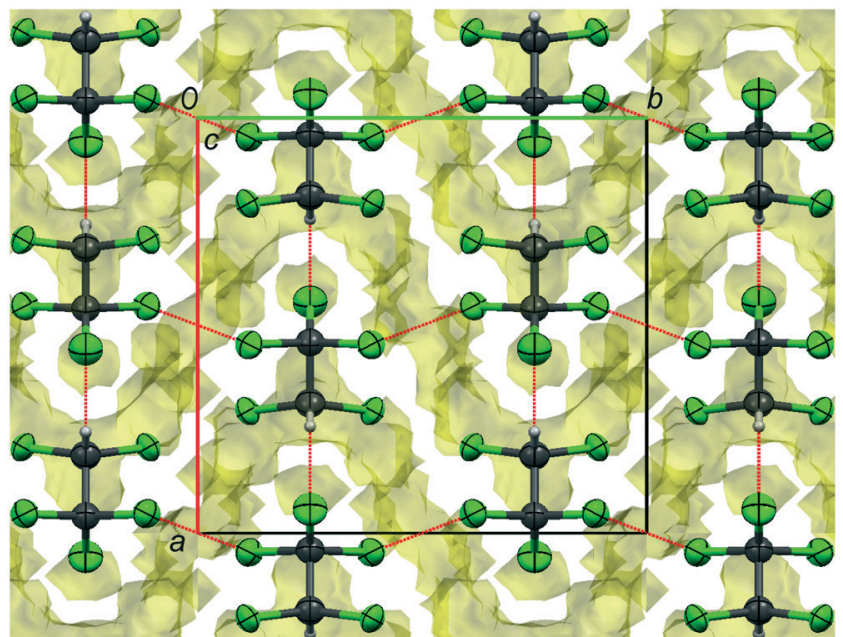

a

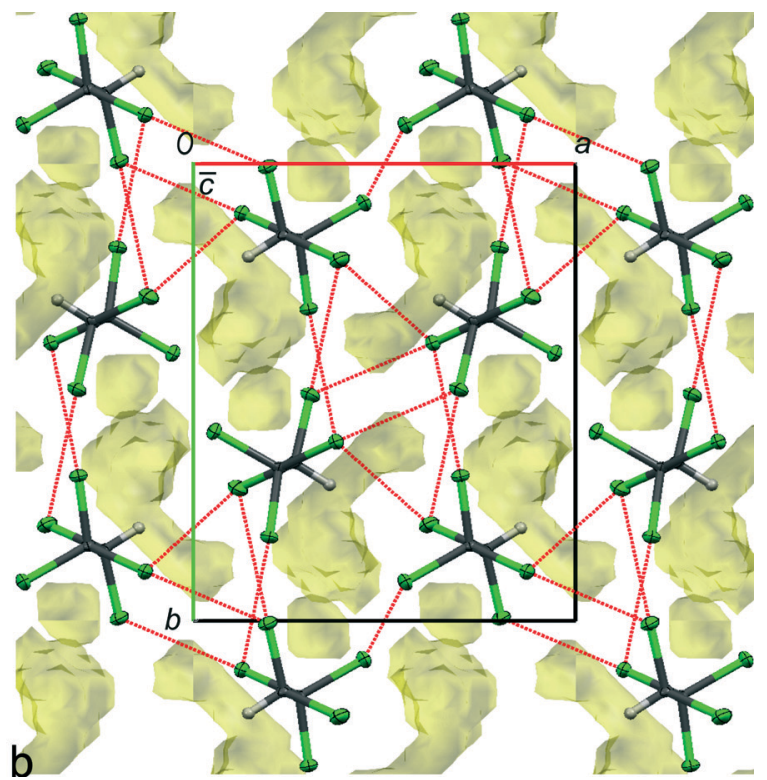

b

Fig. 3 The structures of PCE phase I at $295 \mathrm{~K} / 0.45 \mathrm{GPa}$ (a) and phase II at $295 \mathrm{~K} / 1.00 \mathrm{GPa}$ (b). The intermolecular space accessible to a probing sphere of radius $0.45 \AA$ is indicated in yellow. This void volume is $13.8 \%$ in phase I and $7.8 \%$ in phase II. The dotted red lines indicate the shortest intermolecular $\mathrm{Cl} \cdots \mathrm{Cl}$ and $\mathrm{H} \cdots \mathrm{Cl}$ contacts. Displacement ellipsoids are plotted at the $15 \%$ probability level.

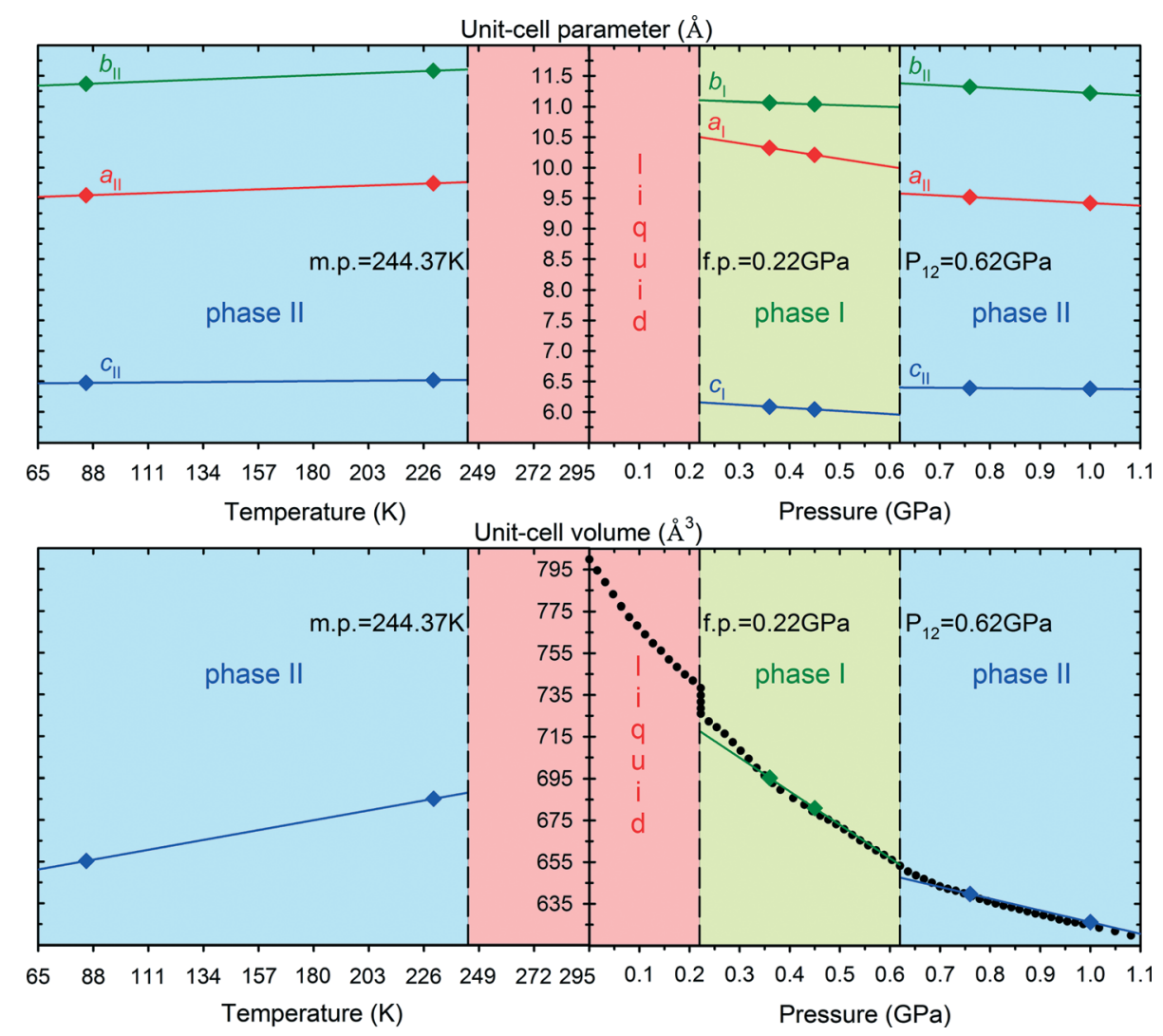

Fig. 4 Temperature and pressure dependence of unit-cell parameters $a, b, c$ and unit-cell volume of PCE. The changes in monoclinic angle $\beta$ are plotted in Fig. S6, ESI.†

remarkable that in phase $\mathrm{I}$, the $\mathrm{C}-\mathrm{H} \cdots \mathrm{Cl}$ bonds are formed, and the $\mathrm{Cl} \cdots \mathrm{Cl}$ contacts do not strictly conform to neither type I nor type II. ${ }^{8}$
The $\mathrm{Cl} \cdots \mathrm{Cl}$ contacts in phase II can be classified as halogen bonds of types I $\left(\mathrm{Cl}_{2} \cdots \mathrm{Cl}^{2}\right)$ and $\mathrm{II}\left(\mathrm{Cl} 1 \cdots \mathrm{Cl} 3^{\mathrm{I}}\right)$ or somewhat distorted from these types (Table 3). The weaker 
Table 2 Dimensions $\left(\AA,{ }^{\circ}\right)$ of the shortest intermolecular contacts in $\mathrm{PCE}-\mathrm{I}$ at $295 \mathrm{~K} / 0.36 \mathrm{GPa}$ and $295 \mathrm{~K} / 0.45 \mathrm{GPa}$

\begin{tabular}{lll}
\hline Temperature, K & $295(2)$ & $295(2)$ \\
Pressure, GPa & $0.36(2)$ & $0.45(2)$ \\
$\mathrm{Cl} 1 \cdots \mathrm{Cl} 1^{\mathrm{I}}$ & $3.438(11)$ & $3.373(10)$ \\
$\mathrm{C} 1-\mathrm{Cl} 1 \cdots \mathrm{Cl}{ }^{\mathrm{I}}$ & $160(2)$ & $162(2)$ \\
$\mathrm{Cl} 1 \cdots \mathrm{Cl} 1^{\mathrm{I}}-\mathrm{C} 1^{\mathrm{I}}$ & $160(2)$ & $162(2)$ \\
$\mathrm{C} 1-\mathrm{Cl} 1 \cdots \mathrm{Cl} 1^{1}-\mathrm{C} 1^{\mathrm{I}}$ & $180.00(1)$ & $180.00(1)$ \\
$\mathrm{H} 1 \cdots \mathrm{Cl} 2^{\mathrm{II}}$ & 3.19 & 2.95 \\
$\mathrm{C} 2-\mathrm{H} 1 \cdots \mathrm{Cl} 2^{\mathrm{II}}$ & 175 & 172 \\
$\mathrm{H} 1 \cdots \mathrm{Cl} 2^{\mathrm{II}}-\mathrm{C} 1^{\mathrm{II}}$ & 79 & 81 \\
$\mathrm{C} 2-\mathrm{H} 1 \cdots \mathrm{Cl} 2^{\mathrm{II}}-\mathrm{C}{ }^{\mathrm{II}}$ & 0.00 & 0.00 \\
$\mathrm{C} 2 \cdots \mathrm{Cl} 2^{\mathrm{II}}$ & $4.17(7)$ & $3.92(6)$ \\
$\mathrm{C} 1-\mathrm{C} 2 \cdots \mathrm{Cl} 2^{\mathrm{II}}$ & $110(3)$ & $118(3)$ \\
$\mathrm{C} 2 \cdots \mathrm{Cl} 2^{\mathrm{II}}-\mathrm{C} 1^{\mathrm{II}}$ & $78(2)$ & $79(2)$ \\
$\mathrm{C} 1-\mathrm{C} 2 \cdots \mathrm{Cl} 22^{\mathrm{II}}-\mathrm{C} 1^{\mathrm{II}}$ & 180.00 & 180.00
\end{tabular}

Symmetry codes: (I) $-x, 1-y,-1-z$; (II) $1 / 2+x, y,-1 / 2-z$.

compression of the $\mathrm{Cl} \cdots \mathrm{Cl}$ contacts in phase II and even the negative compression of $\mathrm{H} \cdots \mathrm{Cl}$ contacts are consistent with the much weaker volume compression of phase II than that of phase I ( $c f$. Fig. 4 and 5).

The shortest intermolecular contacts in the PCE polymorphs can be represented as the diagram of differences between interatomic distances and the sums of van der Waals radii (Fig. 6). ${ }^{5}$ It shows that the shortest contacts (related to the van der Waals radii) are the $\mathrm{Cl} \cdots \mathrm{Cl}$ halogen bonds and only one $\mathrm{CH}^{\cdots} \mathrm{Cl}$ contact in phase I can be compressed to the third shortest value (the third order), before the crystal transforms to phase II. In phase II, the role of $\mathrm{CH}^{\cdots} \mathrm{Cl}$ contacts is considerably reduced to the sixth order. Fig. 6 also illustrates the significantly changing role of contacts $\mathrm{CH}^{\cdots} \mathrm{Cl}$ within phase I. However, the types of shortest contacts in the crystal remain unchanged within the phases and at the phase transition.
Table 3 Dimensions ( $\AA$, o) of the shortest intermolecular contacts in PCEIl at $295 \mathrm{~K} / 0.76 \mathrm{GPa}, 295 \mathrm{~K} / 1.00 \mathrm{GPa}, 230 \mathrm{~K} / 0.1 \mathrm{MPa}$ and $85 \mathrm{~K} / 0.1 \mathrm{MPa}$

\begin{tabular}{|c|c|c|c|c|}
\hline Temperature, K & $295(2)$ & $295(2)$ & $230.0(1)$ & $85.0(5)$ \\
\hline Pressure & $0.76(2) \mathrm{GPa}$ & $1.00(2) \mathrm{GPa}$ & $0.1 \mathrm{MPa}$ & $0.1 \mathrm{MPa}$ \\
\hline $\mathrm{Cl} 1 \cdots \mathrm{Cl}^{\mathrm{I}}$ & $3.415(2)$ & $3.3649(15)$ & $3.5459(12)$ & $3.4407(6)$ \\
\hline $\mathrm{C} 1-\mathrm{Cl} 1 \cdots \mathrm{Cl} 3^{\mathrm{I}}$ & $174.4(6)$ & $175.7(4)$ & $175.02(12)$ & $175.71(6)$ \\
\hline $\mathrm{Cl} 1 \cdots \mathrm{Cl} 3^{\mathrm{I}}-\mathrm{C} 1^{\mathrm{I}}$ & $106.8(2)$ & $107.77(18)$ & $107.56(11)$ & $108.08(6)$ \\
\hline $\mathrm{C} 1-\mathrm{Cl} 1 \cdots \mathrm{Cl} 3^{\mathrm{I}}-\mathrm{C} 1^{\mathrm{I}}$ & $169(3)$ & $179(7)$ & $170(1)$ & $164.1(7)$ \\
\hline $\mathrm{Cl} 3 \cdots \mathrm{Cl} 4^{\mathrm{II}}$ & $3.332(6)$ & $3.281(3)$ & $3.4573(12)$ & $3.3712(6)$ \\
\hline $\mathrm{C} 1-\mathrm{Cl} 3 \cdots \mathrm{Cl} 4^{\mathrm{II}}$ & $121.4(3)$ & $119.6(2)$ & $121.82(11)$ & $121.19(6)$ \\
\hline $\mathrm{Cl} 3 \cdots \mathrm{Cl} 4^{\mathrm{II}}-\mathrm{C} 2^{\mathrm{II}}$ & $161.1(4)$ & $161.9(3)$ & $164.36(12)$ & $162.60(6)$ \\
\hline $\mathrm{C} 1-\mathrm{Cl} 3 \cdots \mathrm{Cl} 4^{\mathrm{II}}-\mathrm{C} 2^{\mathrm{II}}$ & $-168(1)$ & $-170(2)$ & $-172.6(5)$ & $-165.6(2)$ \\
\hline $\mathrm{Cl} 3 \cdots \mathrm{Cl} 5^{\mathrm{III}}$ & $3.438(6)$ & $3.393(2)$ & $3.5698(12)$ & $3.4563(6)$ \\
\hline $\mathrm{C} 1-\mathrm{Cl} 3 \cdots \mathrm{Cl} 5^{\mathrm{III}}$ & $170.2(5)$ & $171.6(6)$ & $170.44(12)$ & $169.85(6)$ \\
\hline $\mathrm{Cl} 3 \cdots \mathrm{Cl}^{5 \mathrm{III}}-\mathrm{C} 2^{2 \mathrm{III}}$ & 113.1(7) & $115.5(4)$ & $115.37(13)$ & $115.25(6)$ \\
\hline $\mathrm{C} 1-\mathrm{Cl} 3 \cdots \mathrm{Cl} 5^{\mathrm{III}}-\mathrm{C} 2{ }^{\mathrm{III}}$ & $60(1)$ & $70(1)$ & $61.2(7)$ & $63.6(3)$ \\
\hline $\mathrm{Cl} 4 \cdots \mathrm{Cl}^{\mathrm{IV}}$ & $3.432(2)$ & $3.3914(14)$ & $3.5457(13)$ & $3.4398(6)$ \\
\hline $\mathrm{C} 2-\mathrm{Cl} 4 \cdots \mathrm{Cl} 5^{\mathrm{IV}}$ & $101.4(3)$ & $101.7(2)$ & $103.77(12)$ & $103.18(6)$ \\
\hline $\mathrm{Cl} 4 \cdots \mathrm{Cl}^{\mathrm{IV}}-\mathrm{C} 2^{\mathrm{IV}}$ & $164.7(8)$ & $166.8(6)$ & $168.01(12)$ & $166.24(6)$ \\
\hline $\mathrm{C} 2-\mathrm{Cl} 4 \cdots \mathrm{Cl} 5^{\mathrm{IV}}-\mathrm{C} 2^{\mathrm{IV}}$ & $-129(1)$ & $-123(1)$ & $-124.8(6)$ & $-121.1(2)$ \\
\hline $\mathrm{Cl} 2 \cdots \mathrm{Cl} 2^{\mathrm{V}}$ & $3.440(7)$ & $3.414(6)$ & $3.5763(18)$ & $3.5438(9)$ \\
\hline $\mathrm{C} 1-\mathrm{Cl} 2 \cdots \mathrm{Cl} 2^{\mathrm{V}}$ & $132.9(7)$ & $130.8(6)$ & $134.48(12)$ & $132.29(6)$ \\
\hline $\mathrm{Cl} 2 \cdots \mathrm{Cl} 2^{\mathrm{V}}-\mathrm{C}^{\mathrm{V}}$ & $132.9(7)$ & $130.8(6)$ & $134.48(13)$ & $132.29(6)$ \\
\hline $\mathrm{C} 1-\mathrm{Cl} 2 \cdots \mathrm{Cl} 2^{\mathrm{v}}-\mathrm{C} 1^{\mathrm{V}}$ & 180.00 & 180.00 & 180.00 & 180.00 \\
\hline
\end{tabular}

Symmetry codes: (I) $1 / 2-x, 1 / 2+y, 1 / 2-z$; (II) $-1 / 2+x, 1 / 2-y, 1 / 2+z$; (III) $-x,-y,-z$; (IV) $1 / 2-x, 1 / 2+y,-1 / 2-z$; (V) $1-x,-y, 1-z$.

\section{Conclusions}

In most haloalkanes investigated so far, high pressure favored the $\mathrm{CH}^{\cdots}$ halogen bonds more than the halogen $\cdots$ halogen contacts; however in the high-pressure phase II of $\mathrm{C}_{2} \mathrm{HCl}_{5}$ the role of the shortest $\mathrm{CH} \cdots \mathrm{Cl}$ bonds is gradually diminished. It can be assumed that the mechanism leading to this type of transformations involves the limited access to the $\mathrm{CH}$ site. The H-bonds have been secluded by the requirement of close packing of the bulky molecules, pushing the $\mathrm{CH}^{\cdots} \mathrm{Cl}$ bonded groups apart. This effect illustrates one of

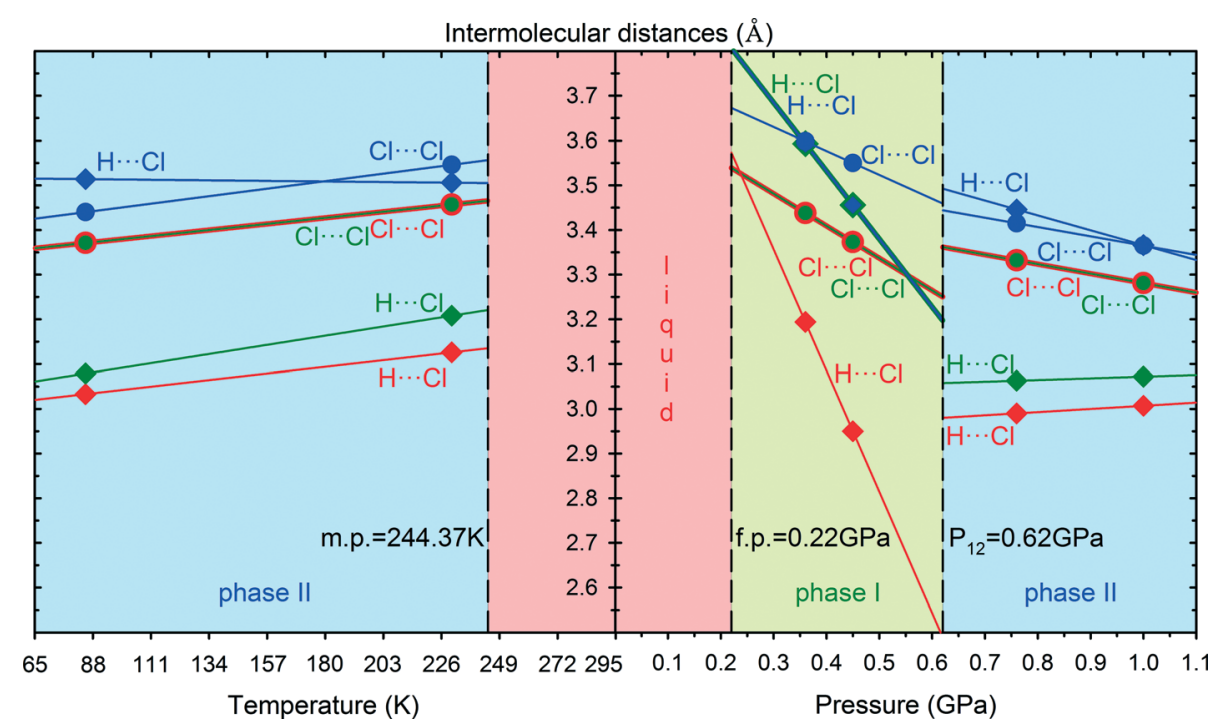

Fig. 5 The shortest $\mathrm{H} \cdots \mathrm{Cl}$ and $\mathrm{Cl} \cdots \mathrm{Cl}$ intermolecular distances $(\AA)$ in phases I and II of PCE. 

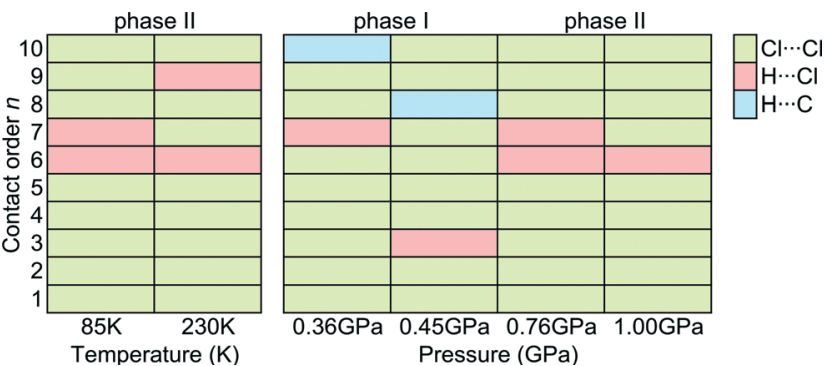

$\mathrm{H} \cdots \mathrm{C}$

Fig. 6 The contact types arranged into a table according to the increasing values (contacts orders) of smallest contact parameters $\delta$, equal to intermolecular distance minus the van der Waals radii, for PCE phases I and II.

possible mechanisms leading to structural transformations, and in an analogous way to the structures with potential $\mathrm{OH} \cdots \mathrm{O}$ bond donors and acceptors, but without the $\mathrm{OH} \cdots \mathrm{O}$ bonds due to steric hindrances. ${ }^{9}$ The room-temperature transition at $0.62 \mathrm{GPa}$ in PCE is one of still rare examples of the structures, where the shortest intermolecular contact in the low-pressure phase (I) is shorter than the shortest contact in the high-pressure phase (II). A similar relation was observed between the shortest $\mathrm{OH} \cdots \mathrm{O}$ bonds in the low- and highpressure phases of sucrose. ${ }^{10}$ Although phases I and II are structurally related, as indicated by the solid-solid transition, unit-cell dimensions, group-subgroup symmetry relation and similar molecular positions, the transformation induces exceptionally strong strain and rearrangement of molecules, which is consistent with the changes in cohesion forces.

\section{Acknowledgements}

The authors are grateful to Ms. B. Sacher-Majewska (Faculty of Chemistry, University of Opole) for performing the DSC analysis of PCE.

\section{Notes and references}

1 (a) D. Seyferth, Organometallics, 2003, 22, 5154-5178; (b) A. Olejniczak, A. Katrusiak and A. Vij, CrystEngComm, 2009, 11, 1073-1080.

2 M. Podsiadło, A. Olejniczak and A. Katrusiak, CrystEngComm, 2014, 16, 8279-8285.

3 (a) J.-S. Chen, R. B. Shirts and W.-C. Lin, J. Phys. Chem., 1986, 90, 4970-4975; (b) M. Bujak, M. Podsiadło and A. Katrusiak, Chem. Commun., 2008, 4439-4441.
4 (a) M. Bujak and A. Katrusiak, CrystEngComm, 2010, 12, 1263-1268; (b) M. Bujak, M. Podsiadło and A. Katrusiak, CrystEngComm, 2011, 13, 396-398; (c) M. Bujak, D. Bläser, A. Katrusiak and R. Boese, Chem. Commun., 2011, 47, 8769-8771; (d) M. Podsiadło, M. Bujak and A. Katrusiak, CrystEngComm, 2012, 14, 4496-4500; (e) Ph. Negrier, M. Barrio, J. Ll. Tamarit, D. Mondieig, M. J. Zuriaga and S. C. Perez, Cryst. Growth Des., 2013, 13, 2143-2148.

5 M. Kaźmierczak and A. Katrusiak, CrystEngComm, 2015, 17, 9423-9430.

6 (a) F. P. A. Fabbiani and C. R. Pulham, Chem. Soc. Rev., 2006, 35, 932-942; (b) E. V. Boldyreva, Acta Crystallogr., Sect. A: Found. Crystallogr., 2008, 64, 218-231; (c) J. Chen, H. Couvy, H. Liu, V. Drozd, L. L. Daemen, Y. Zhao and C.-C. Kao, Int. J. Hydrogen Energy, 2010, 35, 11064-11070; (d) J. Zhao, H. Liu, L. Ehm, D. Dong, Z. Chen, Q. Liu, W. Hu, N. Wang and C. Jin, Inorg. Chem., 2013, 52, 8067-8073; (e) J. Ridout and M. R. Probert, Cryst. Growth Des., 2013, 13, 1943-1948; $(f)$ E. V. Boldyreva, Z. Kristallogr., 2014, 229, 236-245; (g) S. Bergantin, M. Moret, G. Buth and F. P. A. Fabbiani, J. Phys. Chem. C, 2014, 118, 13476-13483; (h) J. Ridout, L. S. Price, J. A. K. Howard and M. R. Probert, Cryst. Growth Des., 2014, 14, 3384-3391; (i) K. Wang, J. Liu, K. Yang, B. Liu and B. Zou, J. Phys. Chem. C, 2014, 118, 8122-8127; ( $j$ ) X. Tan, K. Wang, T. Yan, X. Li, J. Liu, K. Yang, B. Liu, G. Zou and B. Zou, J. Phys. Chem. C, 2015, 119, 10178-10188.

7 (a) A. Bondi, J. Phys. Chem., 1964, 68, 441-451; (b) S. C. Nyburg and C. H. Faerman, Acta Crystallogr., Sect. B: Struct. Sci., 1985, 41, 274-279; (c) S. S. Batsanov, Inorg. Mater., 2001, 37, 871-885.

8 (a) G. R. Desiraju and R. Parthasarathy, J. Am. Chem. Soc., 1989, 111, 8725-8726; (b) V. R. Pedireddi, D. S. Reddy, B. S. Goud, D. C. Craig, A. D. Rae and G. R. Desiraju, J. Chem. Soc., Perkin Trans. 2, 1994, 2353-2360; (c) L. Brammer, E. A. Bruton and P. Sherwood, Cryst. Growth Des., 2001, 1, 277-290; (d) M. Fourmigué, Curr. Opin. Solid State Mater. Sci., 2009, 13, 36-45; (e) F. F. Awwadi, R. D. Willett, K. A. Peterson and B. Twamley, Chem. - Eur. J., 2006, 12, 8952-8960; $(f)$ A. Mukherjee, S. Tothadi and G. R. Desiraju, Acc. Chem. Res., 2014, 47, 2514-2524.

9 (a) C. P. Brock and L. L. Duncan, Chem. Matter., 1994, 6, 1307-1312; (b) C. P. Brock, Acta Crystallogr., Sect. B: Struct. Sci., 2002, 58, 1025-1031.

10 E. Patyk, J. Skumiel, M. Podsiadło and A. Katrusiak, Angew. Chem., Int. Ed., 2012, 51, 2146-2150. 